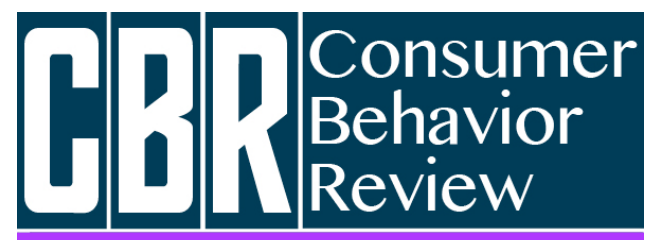

Revista Comportamento do Consumidor
Furtado, E. C. \& Batista, L. L. (2018). Gradientes de colaboração: um estudo de percepção em websites de consumo colaborativo. Consumer Behavior Review, 2(Special Edition), 43-55.
ISSN: 2526-7884

Editor: Prof. Dr. Marconi Freitas da Costa Email da revista: cbr@ufpe.br
Avaliação: Double blind review

Recebido: 31 de Maio de 2018

Aceito: 07 de Agosto de 2018

\title{
GRADIENTES DE COLABORAÇÃO: UM ESTUDO DE PERCEPÇÃO EM WEBSITES DE CONSUMO COLABORATIVO
}

\author{
Eva Carvalho Furtado \\ Leandro Leonardo Batista
}

Eva Carvalho Furtado é Mestre em Ciências da Comunicação pela Escola de Comunicações e Artes da Universidade de São Paulo - USP.

E-mail: evajcfurtado@gmail.com.

Leandro Leonardo Batista é Professor Titular

da Escola de Comunicações e Artes da

Universidade de São Paulo - USP.

E-mail: leleba@usp.br.

Esta pesquisa teve o apoio financeiro da agência de fomento CAPES - Comissão de

Aperfeiçoamento de Pessoal do Nível Superior. Os autores agradecem aos avaliadores pelos comentários para melhoria do artigo.

\begin{abstract}
Resumo
Este trabalho delineia um posicionamento conceitual do consumo colaborativo entre os conceitos de colaboração e cooperação a fim de diferenciar gradientes de colaboração. $\mathrm{Na}$ investigação teórica, o que se encontrou foi uma linha que distingue os graus de colaboração e cooperação por dois fatores: o nível de envolvimento pró-social e a interação entre consumidores. Para analisar esses gradientes de forma empírica, os fatores foram testados em três sites de consumo colaborativo e um site de consumo tradicional. Os resultados mostram que os participantes percebem diferenças de envolvimento entre modelos diferentes de consumo colaborativo.

Palavras-chave: Consumo colaborativo, Gradientes de colaboração, Fatores de colaboração, Cooperação.
\end{abstract}

\section{INTRODUÇÃO}

As pesquisas mais recentes entendem o consumo como um fenômeno cultural que ultrapassa a relação de compra, e também engloba a criação e uso de bens e serviços (McCraken, 2003). Com novas possibilidades de interação surgindo, o consumo vai ganhando cada vez mais gradientes e formas de se apresentar. Uma dessas tendências globais é o consumo colaborativo (Walsh, 2011), que tem, na sua concepção, ideais de coletividade, bem comum e diminuição da produção.

Ao analisar definições e usos do termo (Botsman \& Rogers, 2011; Belk, 2014b; Hamari, Sjöklint \& Ukkonen, 2015; Scaraboto, 2015), podemos sintetizar que o consumo colaborativo envolve uma relação mais próxima entre consumidores $(\mathrm{C} 2 \mathrm{C})$ no que se refere à troca, escambo, empréstimo e reuso de bens materiais e imateriais. Nesse modelo de consumo, quando há envolvimento de empresas, elas ganham um papel 
apenas de intermediária, e o objetivo é pró-social (à medida que estimula um comportamento coletivo em relação ao consumo).

Há vários exemplos bem conhecidos no Brasil e no mundo, como classificados populares de compra e venda de usados, caronas solidárias, aluguel de carros entre pares, brechós, aluguel de acomodações para viajantes, site de trocas de livros e DVDs, salas compartilhadas de trabalho (coworking), financiamento coletivo de projetos (crowdfunding) e outros.

Apesar de a colaboração e o comportamento de troca entre pares ser inerente à sociedade humana, a internet possibilitou novos formatos de participação (Shirky, 2011), o que tornou o conceito de colaboração subjetivo para consumidores da economia compartilhada.

Esse trabalho defende que os modelos de negócio colaborativos abrigam gradientes de colaboração, ou seja, há modelos de colaboração mais intensos e claros para os participantes do que outros. O que flexibiliza as próprias definições do termo.

O presente estudo propõe primeiramente uma breve investigação teórica dos conceitos de colaboração e cooperação pra clarificar gradientes de participação dentro do consumo colaborativo. Posteriormente, para testar esses níveis de colaboração, foi feita uma análise exploratória com consumidores, comparando alguns modelos de consumo colaborativo e também modelos de negócio tradicionais hospedados na internet.

\section{FUNDAMENTAÇÃO TEÓRICA Consumo Colaborativo}

Segundo nossas pesquisas, Felson e Spaeth (1978) usaram o termo "consumo colaborativo" pela primeira vez. Para eles os atos de consumo colaborativo eram aqueles onde uma ou mais pessoas consomem bens econômicos ou serviços no processo de se engajar em atividades conjuntas, por exemplo, beber cerveja com amigos, jantar com familiares ou dirigir para visitar alguém.

Apesar de essa definição estar bem distante do que se entende hoje pelo termo, algo interessante é que Felson e Spaeth (1978) notavam variações no grau da colaboração no consumo. Para eles, os leitores de um jornal cooperam quase nada em comparação com aqueles que celebram um casamento, que podem moldar e elaborar divisões de trabalho.

Mas foi em 2010, com a primeira edição do livro "O que é meu é seu: como o consumo colaborativo vai mudar nosso mundo", escrito por Rachel Botsman e Roo Rogers, que o consumo colaborativo esteve mais presente em artigos científicos e em análises de tendências do tipo "uma das 10 ideias que vão mudar o mundo" (Walsh, 2011).

Hamari et al (2015) trazem duas definições para sintetizar o conceito. A primeira delas diz que o consumo colaborativo é uma atividade baseada em pares para obtenção, doação ou compartilhamento do acesso a bens e serviços, coordenados por serviços online baseados em comunidades. A segunda diz que é um modelo econômico baseado no compartilhamento, troca, escambo, comércio ou aluguel de produtos ou serviços dentro de uma comunidade em oposição à posse.

Para Scaraboto (2015, p. 15), o termo consumo colaborativo se aplica a diversas formas de consumo que não são baseadas em propriedade individual, como o consumo baseado no acesso, compartilhamento organizado e outras formas de consumo caracterizadas pela coletividade e confiança dentro de múltiplos modos de troca e circulação de objetos.

Mas ao contrário do que afirmam Hamari et al (2015), que entendem o fenômeno como um modelo econômico, Scaraboto (2015) acredita que consumidores podem acessar os recursos no consumo colaborativo tanto através de modos de troca baseados no mercado (market-based) quanto em modos não baseados no mercado, ou até mesmo uma combinação de ambos, o que moldaria não só a economia quanto a estrutura social.

Vale lembrar que esse termo "consumo colaborativo" não é o único para descrever uma mesma categoria de negócio e prática de consumo que envolve o compartilhamento. Como resgata Belk (2014a), há autores que estudam o mesmo fenômeno (ou muito similar) com os nomes de the mesh, comercial sharing systems, product-service systems, access-based consumption, consumer participation, sharing economy, entre outros.

Entretanto, a palavra "compartilhamento" para a definição do consumo colaborativo ou da economia compartilhada deve ser usada com cautela. Para Belk (2007) o compartilhamento é o ato e processo de distribuir o que é nosso para os outros e/ou o ato e o processo de receber algo dos outros, sem troca ou compensações. Dividir uma refeição familiar ou hospedar um amigo em casa seria compartilhamento, mas alugar um carro para o vizinho não.

Nessa direção o consumo colaborativo são pessoas coordenando a aquisição e distribuição de 
recursos por compensações, sendo elas monetárias ou não (Belk, 2014b). Ou seja, o consumo colaborativo exigiria reciprocidade o que $o$ diferenciaria do conceito de compartilhamento. Eckhardt e Bardhi (2015) até sugerem que não seja usado o termo economia de compartilhamento (sharing economy), mas economia de acesso (access economy).

Seguindo esse raciocínio, Schor (2014) afirma que muitas organizações têm ansiado por se posicionar dentro da nova onda da economia colaborativa por causa do significado simbólico positivo do compartilhamento, o magnetismo que as tecnologias digitais inovadoras causam. $\mathrm{O}$ Zipcar, por exemplo, empresa de aluguel de carros compartilhados por hora, foi uma das empresas pioneiras na economia colaborativa, e atualmente é uma submarca da Avis, locadora de carros multinacional. O Airbnb, comunidade para hospedagens entre pares ao redor do mundo vale cerca de 10 bilhões de dólares.

Dentre as definições e análises do consumo colaborativo, Botsman e Rogers trazem uma das perspectivas mais romantizadas. Para eles há uma concepção maior que envolve a colaboração e consumo não necessariamente com um retorno financeiro ou tangível. Para eles "estamos reaprendendo a criar valor a partir de recursos compartilhados e abertos de maneiras que equilibram o interesse próprio com o bem da comunidade maior" (Botsman \& Rogers, 2011, p. 59).

Ao nos depararmos nesse cenário de diferentes concepções teóricas, percebemos que até o uso da palavra "colaboração" merece adendos. O que mostra que o consumo colaborativo possibilita muitos gradientes de participação e que talvez, quebrar o fenômeno em fatos menores pode dar outra luz à discussão.

\section{Colaboração e cooperação}

Da mesma forma que o uso da palavra compartilhamento é problemático, o significado de colaboração não é trivial. Os termos colaboração e cooperação geram uma grande variedade de definições e aplicações para diversas áreas do conhecimento. Ao fazer uma breve revisão teórica nota-se que eles podem ser termos de igual significado ou distintos.

Axelrod (1984) entende a cooperação com base na reciprocidade, onde os pares saem ganhando através de uma ajuda mútua. $\mathrm{Na}$ sua visão, cooperação com base na reciprocidade pode se desenvolver mesmo entre antagonistas. Ele cita o exemplo da trincheira da Primeira Guerra Mundial, onde os soldados da linha de frente muitas vezes se abstinham de atirar desde que o outro lado estivesse fazendo o mesmo ("live and let live"), ou seja, a amizade não é necessária para que haja cooperação, desde que haja reciprocidade.

$\mathrm{O}$ autor vê ainda a cooperação como um ato natural e evolutivo do ser humano. Não há necessidade de assumir confiança entre os lados, o uso da reciprocidade pode ser suficiente para fazer da deserção um ato improdutivo. O altruísmo, nesse caso, não é necessário. $\mathrm{E}$, finalmente, não é necessário uma autoridade central para controlar os participantes, a cooperação baseada na reciprocidade pode se auto policiar. Ou seja, se um lado ajuda o outro também ajuda. Se um não ajuda o outro também não ajudará.

Nos estudos de internet, Arnold, Ducate e Kost (2012) analisam a colaboração e a cooperação em sites wikis, aqueles nos quais os usuários podem editar o conteúdo e organizar de forma fácil, como a Wikipédia. No estudo deles, a cooperação permite um trabalho independente de membros de um grupo, que se responsabilizam por subtarefas específicas a serem montadas em um final maior. Colaboração, em oposição, não inclui essa especialização de tarefas, ao contrário, requer trabalhos sincronizados de todos os membros em uma variedade de aspectos do projeto.

Nesse sentido os cooperadores do texto wiki estariam preocupados somente com a parte que se responsabilizaram, revisando somente as suas contribuições ao texto. Os colaboradores, por outro lado, se preocupariam em revisar tanto a sua parte quando as contribuições de outros integrantes do grupo. Nesse sentido, a colaboração seria mais ampla e altruísta que a cooperação.

Apesar de não fazerem distinção entre os termos, Kaufman e Roza (2013) acreditam que a colaboração é um ato consciente, onde os participantes estão cientes do seu papel, e um ato transparente com relação aos objetivos e resultados a serem alcançados.

Jenkins, Ford e Green (2014) não definem com precisão o que significa colaboração, mas relacionam com a reciprocidade entre participantes, assim como Axelrod (1984). Ao comentar a relação das marcas com seus fãs, eles afirmam que tanto os "proprietários" das marcas quanto os fãs se beneficiam da criação de conteúdo novo e não oficial pelos próprios usuários, mesmo que a primeira vista esse trabalho pareça voluntário. 
Shirley Hord (1981) trabalhou o conceito de colaboração no cenário educacional. Para a pesquisadora a colaboração não é possível sem cooperação, mas o inverso não é verdadeiro. A colaboração requer muito mais esforço, mas o seu produto rende mais. A cooperação é possível com o menor esforço, porque ela não requer objetivos comuns. Uma metáfora utiliza por Hord é que sair com alguém é um empreendimento cooperativo, enquanto casar é um colaborativo.

Em consonância com a definição anterior, Winer e Ray (1994) afirmam que a cooperação é um relacionamento de curta duração no qual há um acordo mútuo em que os participantes se beneficiam, mas sem ter necessariamente um objetivo em comum. Já a colaboração é um relacionamento mais durável que exige maior grau de esforço e um objetivo comum compartilhado.

As definições de Winer e Ray (1994) e Hord (1981) desenham uma distinção baseada em intensidade. Ao visualizarmos duas iniciativas enquadradas como consumo colaborativo, como Couchsurfing e Airbnb, é possível distinguir que há uma diferença de intensidade e envolvimento dos consumidores. O Airbnb se aproxima mais de uma iniciativa cooperativa do que o Couchsurfing. No Airbnb o hóspede tem um objetivo de pagar menos do que em um hotel tradicional e o anfitrião tem o objetivo de ganhar dinheiro, no Couchsurfing o hóspede e o anfitrião também tem objetivos distintos, mas tem um objetivo em comum da partilha de experiências através da aproximação de culturas.

\begin{tabular}{|c|c|c|}
\hline & COLABORAÇÃO & COOPERAÇÃO \\
\hline Axelrod (1984) & - Não define & $\begin{array}{l}\text { - Reciprocidade } \\
\text { - Benefício mútuo } \\
\text { - Altruísmo não é necessário }\end{array}$ \\
\hline Arnold et al (2012) & $\begin{array}{l}\text { - Preocupação coletiva } \\
\text { - Amplo } \\
\text { - Altruísta }\end{array}$ & $\begin{array}{l}\text { - Preocupação individual } \\
\text { - Restrito } \\
\text { - Não altruísta }\end{array}$ \\
\hline Kaufman e Roza (2013) & $\begin{array}{l}\text { - Ato consciente } \\
\text { - Objetivos conscientes }\end{array}$ & - Não define \\
\hline Jenkins, Ford \& Green (2014) & $\begin{array}{l}\text { - Reciprocidade } \\
\text { - Entre membros de uma comunidade } \\
\text { - Benefício mútuo }\end{array}$ & - Não define \\
\hline Hord (1981) & $\begin{array}{l}\text { - Mais esforço } \\
\text { - Resultado rende mais } \\
\text { - Requer objetivos comuns }\end{array}$ & $\begin{array}{l}\text { - Menos esforço } \\
\text { - Resultado rende menos } \\
\text { - Não requer objetivos comuns }\end{array}$ \\
\hline Winer \& Ray (1994) & $\begin{array}{l}\text { - Mais durável } \\
\text { - Maior grau de esforço } \\
\text { - Objetivo comum }\end{array}$ & $\begin{array}{l}\text { - Menos durável } \\
\text { - Menos esforço } \\
\text { - Acordo mútuo sem objetivo comum }\end{array}$ \\
\hline
\end{tabular}

Fonte: Elaborado pelos autores.

Figura 1: Quadro comparativo das diferenças por autores dos conceitos de colaboração e cooperação.

O que também diferenciaria os dois conceitos, que são considerados formatos de participação e interação, é o nível de envolvimento de cada um. Onde a colaboração supõe um envolvimento maior dos participantes. Envolvimento aqui entendido como um estado psicológico subjetivo que reflete a importância e relevância pessoal de algum assunto, propaganda, produto, ou trabalho individual (Barki \& Hartwick, 1994).

O conceito de envolvimento, para os nossos estudos de consumo colaborativo, deve ser entendido como a relevância pessoal de um trabalho individual em benefício do grupo. Já que a teorização do consumo colaborativo (Botsman \& Rogers, 2011) pressupõe o consumo como possível bem coletivo de forma a beneficiar a comunidade, cidade ou meio ambiente.

\section{Gradientes de colaboração}

Mesmo Botsman e Rogers (2011) sendo uma bibliografia não acadêmica, eles trouxeram uma contribuição relevante para o estudo do consumo colaborativo: a tentativa de classificar formatos 
para serem estudados separadamente. Eles criaram três classes para diferenciar as iniciativas de consumo colaborativo: mercados de redistribuição, sistemas de serviços de produto (SSP) e os estilos de vida colaborativos. Essa classificação será utilizada nesse trabalho para compreendermos as variações dos comportamentos de colaboração e cooperação dentro das iniciativas do consumo colaborativo.

Nos mercados de redistribuição o usuário passa a propriedade de um produto para outro usuário, seja em trocas livres ou na compra e venda de produtos usados. As mídias digitais possibilitam essa troca com facilidade, em sites como eBay, Freecycle, Craiglist. No Brasil: Mercado Livre, OLX, Enjoei. Esse modelo é muito próximo do que Belk (2009) chama simplesmente de troca de mercadoria (commodity exchange).

Os sistemas de serviços de produtos são os que mais se aproximam do modelo que Bardhi e Eckhardt (2012) chamam de consumo baseado no acesso (access-based consumption), ou seja, acesso no lugar da posse. Essa categoria se refere a empresas como as lavanderias coletivas, sistemas de aluguel de carros e bicicletas. Ou consumidores compartilhando entre pares, como o site brasileiro Tem Açúcar que permite pedir emprestado para os seus vizinhos algo que você precise usar temporariamente, como uma barraca de acampamento. Ou até mesmo modelos mais conhecidos e consolidados como Netflix e Uber.

Os estilos de vida colaborativos seriam os modelos onde há a partilha de bens não tangíveis, como tempo, espaço, habilidades e até dinheiro. Dois dos exemplos mais fortes dessa categoria são o Couchsurfing e o Airbnb, sites de hospedagem doméstica. Mas também há o Bliive, que permite trocar conhecimento através de moedas de tempo.

Essas três categorias abrangem uma gama de serviços e modelos muito distintos, e como vimos anteriormente com os conceitos de colaboração e cooperação, eles não têm, de forma geral, o mesmo nível de envolvimento e de esforço por parte dos participantes. O que quer dizer que dentro do consumo colaborativo há comportamentos cooperativos e colaborativos. A maioria dos modelos, na verdade, opta por facilitar a participação de forma curta, rápida e com pouco envolvimento.

É válido abrir um parêntese para esclarecer uma decisão conceitual de entender o comportamento colaborativo, dentro do consumo colaborativo, como aquele onde os participantes entendem sua ação como parte de um bem coletivo, que vá de alguma forma influenciar também a sua comunidade ou outras pessoas ao seu redor, e não somente o seu par direto em uma transação de consumo.

Os mercados de redistribuição e os sistemas de serviços de produtos demonstram um caráter cooperativo por não requerer envolvimento com o projeto, por não exigir tanto esforço de interação e por não ter, necessariamente, um objetivo em comum. No OLX, por exemplo, vendedor e comprador têm objetivos distintos e o envolvimento é pequeno.

Já os estilos de vida colaborativos se assemelham mais ao conceito de colaboração. O site brasileiro Bliive, por exemplo, permite a troca de conhecimento entre usuários. Nele é possível oferecer uma aula ou um conhecimento em troca de uma moeda virtual que pode ser usada dentro da plataforma para receber conhecimento de outro participante da rede. Como por exemplo, dar uma hora de aula de piano e ganhar crédito para ter outra hora de aula de yoga. Nesse caso o envolvimento e o esforço são altos pela quantidade de tempo que se investe na comunidade e por todas as trocas serem válidas somente dentro da plataforma, o que fortalece o grupo e o senso de pertencimento.

Entretanto, nota-se que um comportamento colaborativo pode existir dentro de um modelo que tende ao cooperativo e vice versa. Isso quer dizer que apesar de os mercados de redistribuição e os sistemas de serviços de produtos serem, por definição, mais próximos do conceito de cooperação, os participantes podem agir de forma colaborativa.

O projeto Bike Sampa, por exemplo, por definição seria cooperativo por não exigir um alto envolvimento e nem um objetivo em comum entre participantes. Cada um tem um objetivo individual ao utilizar as bicicletas. Entretanto, há aqueles que utilizam por entender que há sim um objetivo comum: melhorar o trânsito da cidade; diminuir a poluição ambiental, reduzir o número de carros etc.

Essa hipótese de que há modelos tanto colaborativos quanto cooperativos não representa uma oposição, mas sim um gradiente, ou seja, a medida que aumenta a participação e o envolvimento com a comunidade, e o objetivo comum se torna mais saliente que o objetivo individual, uma iniciativa é mais colaborativa do que cooperativa. 


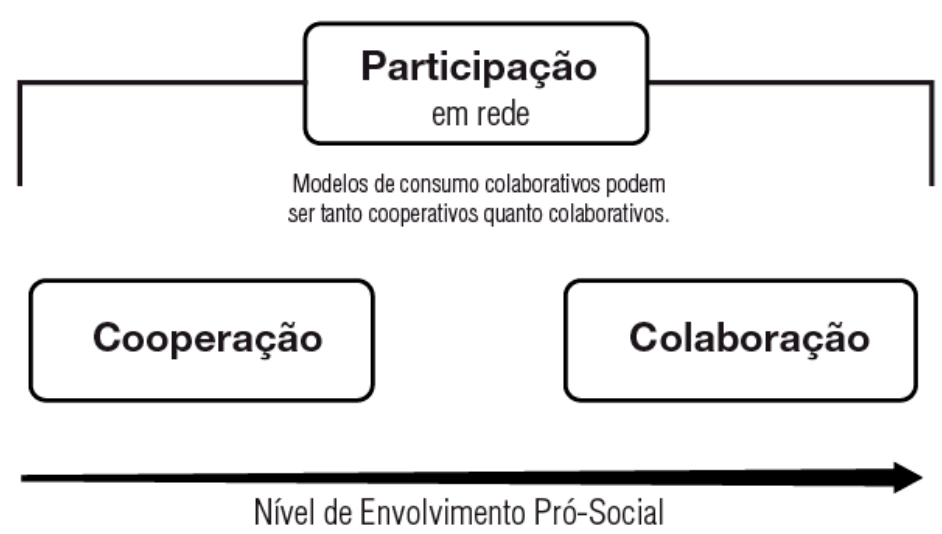

Fonte: Elaborado pelos autores.

Figura 1: Participação e níveis de envolvimento.

Entretanto, Kaufman e Roza (2013) nos lembram que, com a internet, a nossa sociedade está criando uma relação inédita entre indivíduos e coletivo onde é mais claro a interdependência e os laços com outros usuários e instituições. Não devemos, portanto, usar classificações para diminuir a relevância de um ou outro modelo. A participação já é por si só importante, independentemente se os consumidores estão cooperando ou colaborando.

\section{MÉTODO \\ Fatores de colaboração}

Partimos do pressuposto que há gradientes de colaboração dentro do consumo colaborativo, ou seja, não há apenas dois estados bem definidos colaboração e cooperação - mas uma variação entre esses estados. A partir daí viu-se necessária uma análise exploratória para entender o empirismo desse pressuposto, para tanto sugerimos fatores que possam ajudar a criar marcos dentro desse gradiente e testar se os usuários de fato percebem distinções entre modelos de consumo colaborativo, quanto aos fatores sugeridos.

Baseado na discussão teórica sobre as definições de consumo colaborativo, colaboração e cooperação percebemos que há duas características que podem cruzar os conceitos e nos ajudar a reconhecer uma iniciativa de consumo colaborativo: (1) o envolvimento pró-social, onde se cria um senso de comunidade de usuários em torno da troca e acesso a produtos e serviços; (2) e a relação e interação entre consumidores (consumer-to-consumer), onde o papel da empresa torna-se intermediário ou inexistente.

Acreditamos que esses dois fatores podem ser medidos através de escalas de sete pontos e dar base para entender os gradientes de colaboração em modelos individuais e categorias de consumo colaborativo.

O primeiro fator - o nível de envolvimento prósocial - une o senso de comunidade e a noção de ajuda mútua. Esse fator testa o quanto as pessoas se sentem parte de um grupo ao participarem de uma iniciativa de consumo colaborativo. Por exemplo, se alguém se envolve num mutirão de limpeza de um parque público provavelmente terá uma noção de comunidade em um nível diferente de um usuário do Facebook com a sua rede de contatos. Mas os dois, provavelmente, entenderão que estão em algum tipo de comunidade.

$\mathrm{O}$ segundo fator - a interação entre consumidores - baseia-se no quanto a empresa perde seu papel na relação de consumo. Por exemplo, um usuário da OLX interage muito menos com a empresa e mais com os outros compradores e vendedores, já que o portal não faz vendas diretas, só possibilitando o contato entre interessados.

Sendo assim, dentro de cada fator de análise utilizou-se uma escala de sete pontos (de 1 a 7) que pudesse demonstrar uma relação fraca (de 1 a 2), média (de 3 a 5) ou forte (entre 6 e 7), como mostra a figura a seguir: 


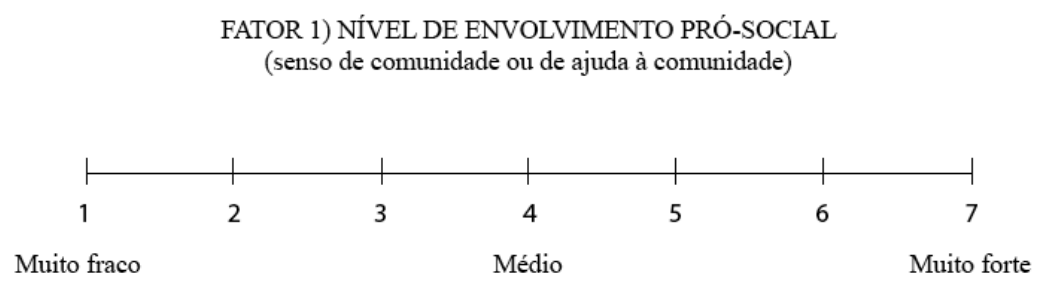

FATOR 2) INTERAÇÃO ENTRE CONSUMIDORES

(comparada à interação empresa-consumidor)

$\begin{array}{ccccccc}1 & \mid & \mid & \mid & & \mid & \\ 1 & 2 & 3 & 4 & 5 & 6 & 7 \\ \text { Muito fraco } & & & \text { Médio } & & & \text { Muito forte }\end{array}$

Fonte: Elaborado pelos autores.

Figura 3: Escala de sete pontos dos fatores de colaboração no consumo colaborativo.

Se somarmos os resultados da aplicação das duas escalas, teremos um fator resultante da soma dos dois, que nomeamos de nível de colaboração para as iniciativas de consumo colaborativo. Esse novo fator pode ir de 2 a 14 e os resultados gerarão uma classificação de 5 grupos que podem ser vistos na figura 4 a seguir.

\section{RESULTADOS POSSÍVEIS} FATOR: NÍVEL DE COLABORAÇÃO

2 a 3: altamente cooperativo

4 a 6 : razoavelmente cooperativo

7 a 9: cooperativo-colaborativo

10 a 12: razoavelmente colaborativo

13 a 14: altamente colaborativo

Fonte: Elaborado pelos autores.

Figura 4: Resultados possíveis e classificação para o nível de colaboração.

Entende-se então, que esse fator vai de um nível altamente cooperativo a um nível altamente colaborativo, ou seja, do ponto de vista do consumidor, uma iniciativa que tem um objetivo social e comunitário e com grande participação dos usuários é altamente colaborativa. Entretanto, negócios que tem um apelo de interação entre pares com objetivos finais unicamente individuais e onde o usuário enxerga mais a empresa do que os outros usuários são altamente cooperativos.

Quanto mais um modelo de negócio é cooperativo, mais ele se parece com modelos tradicionais de serviços onde há um acordo contratual entre as partes - consumidor e empresa - e onde menos se vê a relação comunitária, entre pares. Quanto mais um modelo de negócio é colaborativo mais ele se parece com a perspectiva de Botsman e Rogers (2011) de modelos que beneficiam a comunidade, o indivíduo e o meio ambiente de forma consciente e para o privilégio do bem comum.

\section{Estímulo}

$\mathrm{Na}$ escolha de qual estímulo utilizaríamos para testar as variáveis de colaboração, decidimos intermediar o mínimo possível a interpretação dos participantes, dando inputs amplos que não necessitassem de muitas explicações preliminares. A percepção é um processo dinâmico que busca integrar toda e qualquer informação que possa auxiliar a compreender e classificar o estímulo (Sternberg, 2000). Desta forma esperávamos uma integração entre o que seria apresentado e o que poderia ser construído a partir das informações.

Os estudos da Gestalt nos oferecem meios para entender como a soma das partes não é igual ao todo e como nossa percepção é influenciada pela disposição dos elementos presentes nos estímulos que recebemos (Wong, 2010). A solução encontrada foi mostrar a própria homepage dos sites de consumo colaborativo para que fosse lida e interpretada como um todo antes de fazer as perguntas relacionadas aos nossos fatores.

\section{Procedimento}

Se tratando de uma análise exploratória, este trabalho não tem ambição de ter validade 
probabilística, e sim testar se os participantes conseguem interpretar diferenças entre iniciativas de consumo colaborativo, através do estímulo visual e textual das homepages, no que diz respeito aos fatores de colaboração.

Foi selecionado um exemplo de site de cada categoria de consumo colaborativo de Botsman e Rogers (2011) para submeter à avaliação dos participantes, totalizando três homepages de sites brasileiros de consumo colaborativo e um site de consumo tradicional.

Nós acrescentamos um website de consumo tradicional para testar as variáveis de colaboração em um estímulo não colaborativo, ou seja, esperando que haja notas mais baixas para um website que não pressupõe colaboração.

Para selecionar os sites colaborativos que iríamos utilizar, alguns critérios foram adotados: (1) deveriam ser sites que tivessem uma proposta de simples compreensão; (2) não poderiam ser extremamente conhecidos, para não enviesar a resposta; (3) deveriam ter preferencialmente um layout minimalista para facilitar a leitura e a compreensão do serviço; e (4) todos deveriam estar em português.

Para selecionar o site tradicional além dos quatro critérios apresentados acima, também deveria ser um modelo comercial amplamente difundido offline e online, como um serviço de venda de mercadorias eletrônicas.

Fizemos um levantamento de 30 sites, sendo 8 da categoria mercado de redistribuição, 12 de sistemas de serviços de produtos, e 10 de estilos de vida colaborativos. Dentre eles, selecionados 3 que se encaixavam melhor nos critérios de inclusão. Portanto, os sites selecionados foram: (1) Enjoei.com.br (mercado de redistribuição), site de compra e venda de produtos usados de vestiário; (2) Fleety.com.br (sistema de serviço de produtos), serviço de aluguel de carros entre pares; (3) Bliive.com (estilos de vida colaborativos), onde os usuários podem oferecer horas de conhecimentos diversos em troca de horas de crédito para usar em outra aula de seu interesse; (4) Girafa.com.br (site não-colaborativo) site de vendas de produtos eletrônicos, eletrodomésticos, telefonia e informática.

Duas perguntas foram elaboradas para cada site, totalizando 8 perguntas, que se referiam aos dois fatores propostos (envolvimento pró-social e interação entre consumidores). São elas:

1. Você considera que as pessoas ao utilizarem esse site criam uma comunidade de usuários que se ajudam? Responda numa escala de 1 a 7 , onde 1 seria "definitivamente não há uma comunidade aqui" e 7 seria "definitivamente há uma comunidade online aqui".

2. Você considera que nesse site os usuários interagem mais com outros usuários do que com a própria empresa? Responda numa escala de 1 a 7 , onde 1 seria "Definitivamente não, a interação entre empresa e usuário é muito maior" e 7 seria "Definitivamente sim, os usuários interagem mais entre si e o site é só um intermediário".
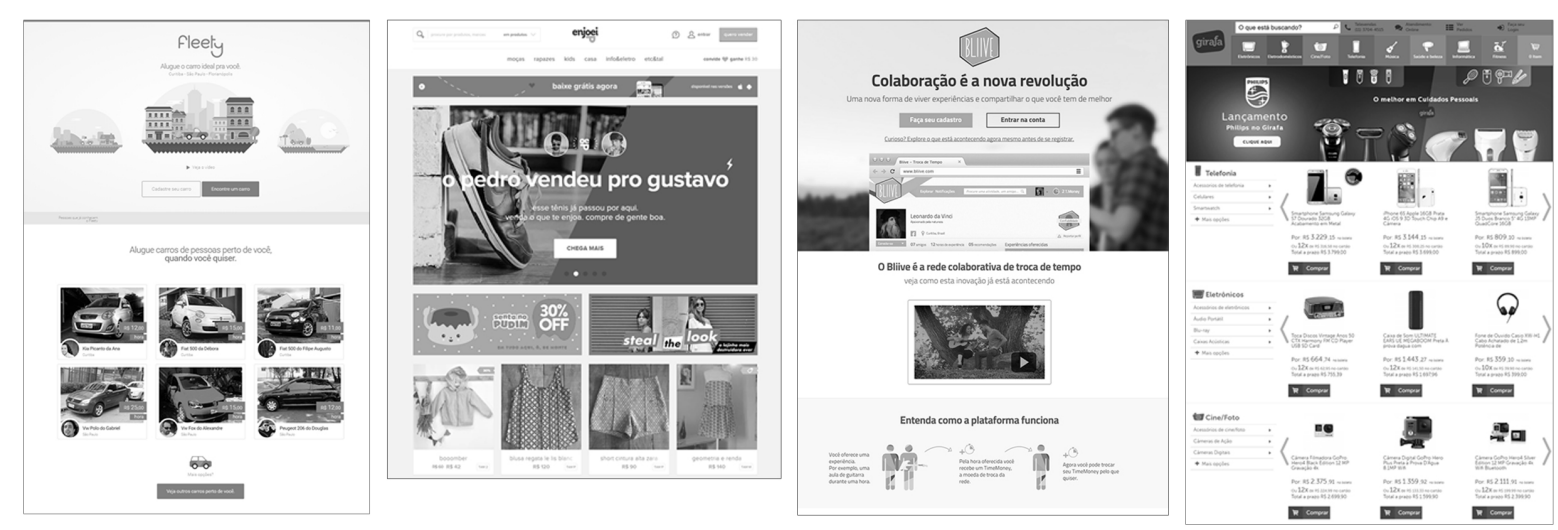

Fonte: Elaborado pelos autores. Nota: Da esquerda para direita: Fleety, Enjoei, Bliive, Girafa.

Figura 5: Homepages vistas pelos participantes. 


\section{Participantes}

A amostragem se deu por conveniência, mas com base nos dados de uma pesquisa realizada pelo site de financiamento coletivo Catarse. A empresa realizou um levantamento para conhecer o público-alvo do site. Como se trata de um exemplo forte do consumo colaborativo no Brasil, adotaremos esses dados para validar o perfil da nossa amostra de pesquisa.

Dos usuários do site Catarse no Brasil, 63\% estão concentrados na região sudeste. As faixas etárias entre 25 a 40 anos concentram $56 \%$ dos adeptos, o que corresponde à faixa etária que preferencialmente iremos utilizar. Quanto à escolaridade, $94 \%$ dos entrevistados estão entre o ensino superior incompleto e a pós-graduação, e $74 \%$ dos pesquisados tem renda mensal média de até seis mil reais (Catarse, 2014).

Sendo assim, a nossa amostra priorizou pessoas que, baseadas na pesquisa do site Catarse, tem maior tendência de conhecer o consumo colaborativo, ou estratégias de colaboração pela internet. Esse perfil não foi fator de inclusão na pesquisa, apenas um direcionamento, pois o questionário foi constituído ao ponto de ser acessível e entendível mesmo por quem não tem afinidade com iniciativas de consumo colaborativo.

Tivemos 156 participantes válidos, sendo 97 mulheres e 59 homens $(62,2 \%$ e $37,8 \%)$, respectivamente, o que é uma proporção aceitável para a média de homens e mulheres no Brasil. A idade ficou numa média de 28,14 anos (o perfil do Catarse está entre 25 e 40 anos).

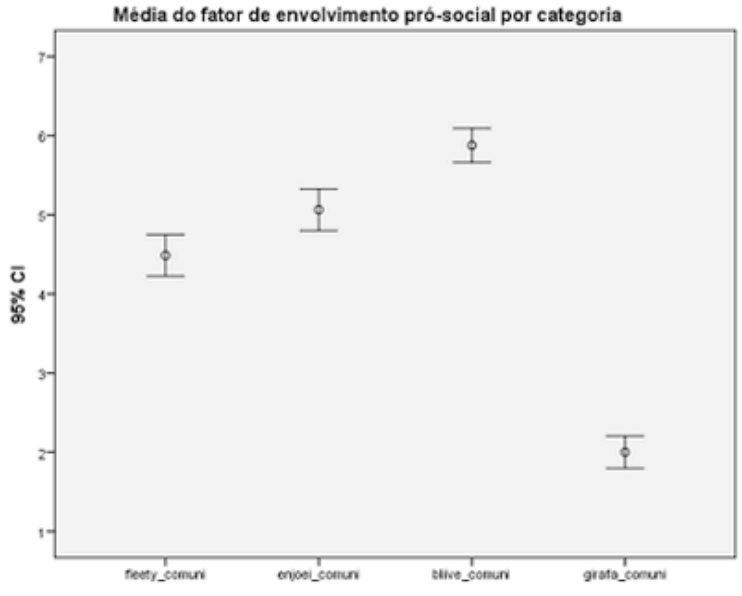

Fonte: Elaborado pelos autores.

Figura 6: Gráficos de barras de erro dos fatores de envolvimento pró-social e interação entre consumidores.

Cada barra de erro representa um site de uma categoria, o que significa que os resultados não

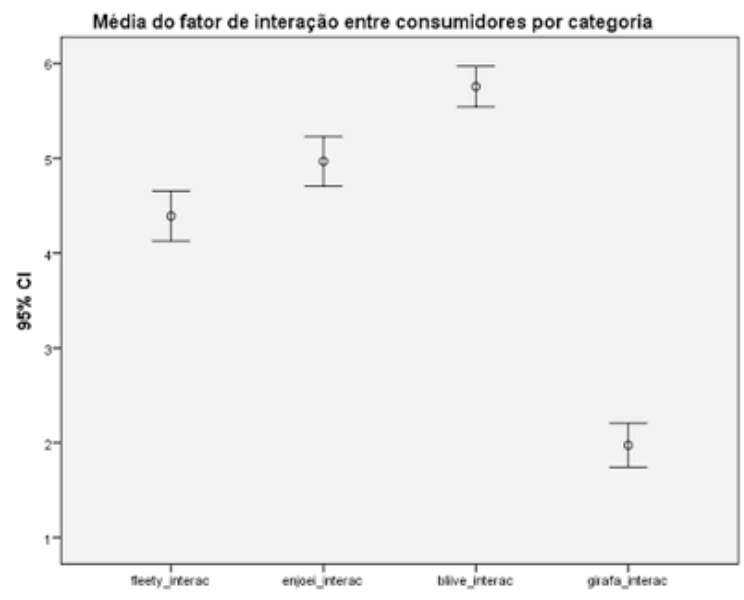

A escolaridade, devido à característica da amostragem por conveniência, distancia-se do que vemos na sociedade brasileira, mas se mantém próximo do que o site Catarse (2014) identificou como seu público-alvo da colaboração: nenhum entrevistado não frequentou a escola $(0 \%) ; 1,3 \%$ tem ensino fundamental completo; $15,4 \%$ tem ensino médio completo; $44,9 \%$ tem ensino superior completo e 38,5\% tem pós-graduação completa.

Quanto à renda, também estamos próximos do perfil encontrado pelo público do site Catarse: $3,2 \%$ entrevistados ganham menos de 1 salário mínimo; 17,9\% recebem até 3 salários mínimos; $25,6 \%$ até 6 salários mínimos; $18,6 \%$ ganham até 9 salários mínimos; $19,9 \%$ até 15 salários mínimos e 14,7\%recebem acima de 15 salários mínimos.

\section{RESULTADOS}

Alguns testes estatísticos, principalmente no que diz respeito à comparação de médias, podem ser feitos simplesmente com a análise do gráfico de barras de erro e seus respectivos intervalos de confiança. Eles servem como testes post hoc ${ }^{1} \mathrm{de}$ uma ANOVA, nos dizendo onde está a diferença de médias. Portanto usaremos apenas gráficos para demonstrar os resultados obtidos e a diferença de média das categorias estudadas, ou seja, se há categorias que são mais colaborativas e outras mais cooperativas.

As figuras 6 e 7, a seguir, trazem gráficos que mostram o resultado dos fatores individuais - de envolvimento pró-social e relação entre consumidores -, e do fator geral de colaboração. podem ser generalizados de uma iniciativa para uma categoria do consumo colaborativo. Apenas 
podemos usar as respostas como indícios de uma hipótese de que há diferenças por categoria.

As variáveis que começam com o prefixo "fleety_" representam a categoria sistema de serviço de produtos, as que começam com o prefixo "enjoei_" representam a categoria mercado de redistribuição. Aquelas, em cada gráfico, que começam com "bliive_" dizem respeito à categoria estilo de vida colaborativo e aquelas que utilizam o prefixo "girafa_" representam um site de vendas tradicional.

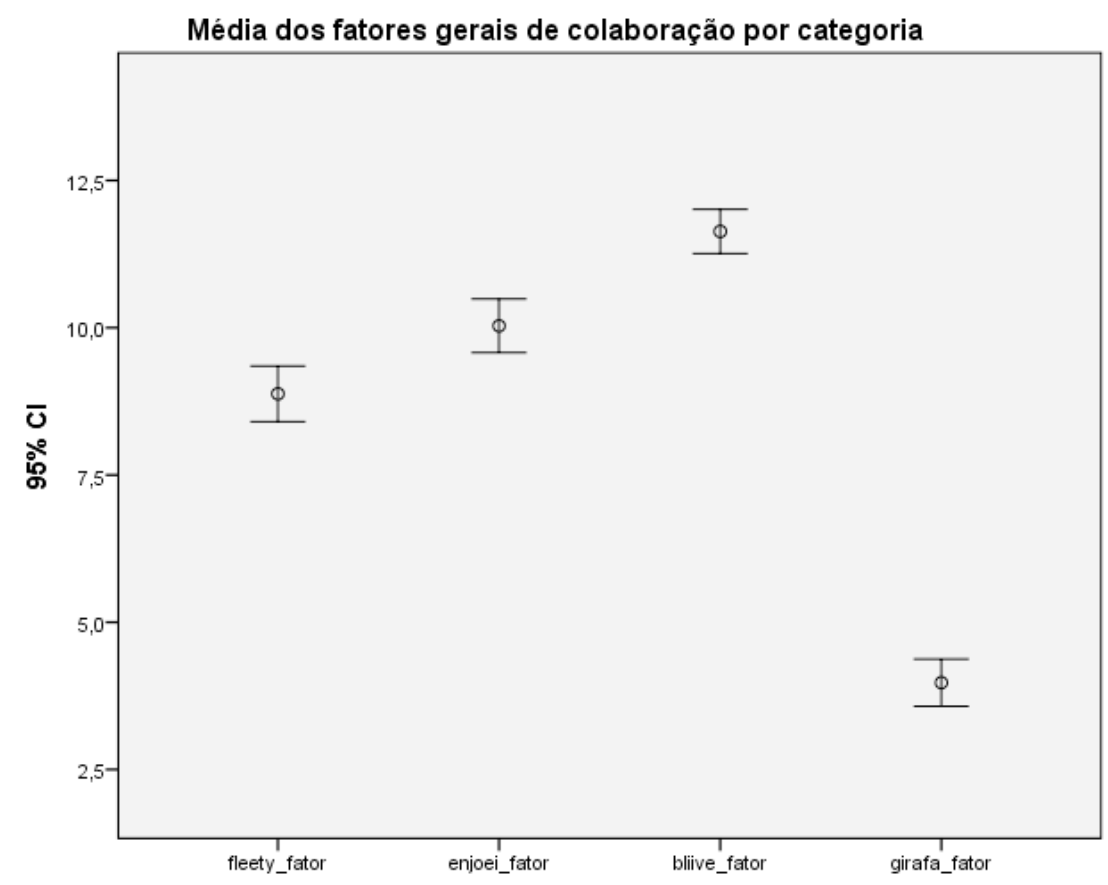

Fonte: Elaborado pelos autores. Nota: Diferença de médias entre as categorias em relação ao fator geral de colaboração, que é a somatória dos fatores envolvimento pró-social e interação entre consumidores.

Figura 7: Gráfico de barras de erro

O ponto no centro de cada barra de erro indica a média tida naquela escala. Os limites superiores e inferiores ao ponto representativo de média são os intervalos de confiança. Se os intervalos não se cruzarem com os das outras categorias podemos afirmar que as médias são diferentes, ou seja, que há uma diferença entre os grupos.

\section{Tabela 1}

Dados descritivos das variáveis

\begin{tabular}{c|c|c|c|c|c}
\hline Variável & Mínimo & Máximo & Média & Desvio Padrão & IC de 95\% para a média \\
\hline fleety_comuni & 1 & 7 & 4,49 & 1,656 & $4,23-4,75$ \\
\hline fleety_interac & 1 & 7 & 4,39 & 1,664 & $4,13-4,65$ \\
\hline enjoei_comuni & 1 & 7 & 5,06 & 1,664 & $4,80-5,33$ \\
\hline enjoei_interac & 1 & 7 & 4,97 & 1,652 & $4,71-5,23$ \\
\hline bliive_comuni & 1 & 7 & 5,88 & 1,355 & $5,66-6,09$ \\
\hline bliive_interac & 1 & 7 & 5,76 & 1,351 & $5,54-5,97$ \\
\hline girafa_comuni & 1 & 7 & 2,00 & 1,290 & $1,80-2,20$ \\
\hline girafa_interac & 1 & 7 & 1,97 & 1,463 & $1,74-2,21$ \\
\hline Fleety_fator & 2 & 14 & 8,87 & 2,98 & $8,40-9,35$ \\
\hline Enjoei_fator & 2 & 14 & 10,03 & 2,88 & $9,57-10,48$ \\
\hline Bliive_fator & 2 & 14 & 11,63 & 2,37 & $11,25-12,01$ \\
\hline Girafa_fator & 2 & 14 & 3,97 & 2,53 & $3,57-4,37$
\end{tabular}

Fonte: Elaborado pelos autores. 
Podemos observar na figura 7 que os valores do site Fleety, Bliive e Girafa não coincidem nos intervalos de confiança, isso quer dizer que há uma diferença real entre eles quanto à interpretação dos usuários sobre o nível de colaboração.

Dentre eles, o site Girafa foi o que recebeu as menores notas, ou seja, é o site mais distante possível do conceito de colaboração, o que é coerente por se tratar de um site tradicional de vendas (média geral de 3,97). O site Fleety, representante da categoria sistema de serviço de produtos, apresentou uma média de 8,87 o que lhe enquadraria na classe cooperativo-colaborativo e o Bliive, com a maior média entre os outros $(11,63)$, seria enquadrado na classe razoavelmente colaborativo. Na tabela 1 é possível ver todos os valores obtidos por variável.

Os gráficos também mostram que o site Enjoei coincide seu intervalo de confiança com o site Fleety, o que quer dizer, que não há uma diferença estatisticamente significante entre eles, podendo os dois terem a mesma pontuação na escala. Isso sugeriria que as categorias de sistema de serviço de produtos e mercado de redistribuição possam ter um nível de colaboração muito próximo, entre o cooperativo-colaborativo e o razoavelmente colaborativo.

Entretanto o site Enjoei é também estatisticamente diferente do site Bliive e do Girafa, ou seja, o nível de colaboração deles é diferente do ponto de vista do usuário. Sendo o Bliive aquele que é considerado mais colaborativo e o site Girafa o menos. Esse resultado está em conformidade com o que afirmava Belk (2014a), que muitas iniciativas da categoria estilo de vida colaborativo estão de acordo com o termo compartilhamento, e mais próximas também do conceito de colaboração.

A tabela 2, abaixo, mostra o resultado final dos sites estudados dentro no nível de colaboração. $\mathrm{O}$ site Enjoei recebeu nota 10,03, equivalente ao grupo razoavelmente colaborativo, o site Fleety recebeu nota 8,87 , ficando no grupo cooperativocolaborativo e o site Bliive com a nota mais alta $(11,63)$ se enquadra no grupo razoavelmente colaborativo.

Tabela 2

Comparação das notas para o nível de colaboração.

\begin{tabular}{c|c} 
Site/Categoria & Nota e classificação para o nível de colaboração \\
\hline Enjoei (Mercado de Redistribuição) & 10,03 (Razoavelmente colaborativo) \\
\hline Fleety (Sistema de serviço de produto) & 8,87 (Cooperativo-colaborativo) \\
\hline Bliive (Estilo de vida colaborativo) & 11,63 (Razoavelmente colaborativo) \\
\hline Girafa (Não colaborativo) & 3,97 (Altamente cooperativo) \\
\hline
\end{tabular}

Fonte: Elaborado pelos autores.

O site Girafa ficou com uma média de 3,97, o que faria ele se enquadrar em altamente cooperativo. Entretanto ele não corresponde às características básicas de uma iniciativa de consumo colaborativo e foi utilizado aqui para ilustrar a diferença que os fatores poderiam gerar.

De qualquer forma podemos inferir que os entrevistados veem os sites tradicionais de forma bem diferente dos sites colaborativos. Mas não é possível saber se a atitude em relação a esses sites é positiva ou negativa muito menos se essa atitude poderia se transformar em comportamento através da adesão a essas iniciativas.

É bom destacar mais uma vez que cada variável vista diz respeito a apenas um site, e não a categoria inteira. $\mathrm{O}$ ideal seria testar essas variáveis em mais exemplos por categoria, o que é uma sugestão para futuros trabalhos.

Esses fatores podem auxiliar futuros estudos sobre consumo colaborativo mas não minimizam a importância de iniciativa cooperativas em detrimento de iniciativas colaborativas, e nem excluem a utilização de outros métodos de classificação ou o aperfeiçoamento dos fatores apresentados.

\section{CONSIDERAÇÕES FINAIS}

Observarmos durante esse trabalho que assim como a definição de compartilhamento de Belk (2007) pode ser utilizada de forma errada na literatura, o termo colaboração também tem nuances ao se referir ao consumo colaborativo. $\mathrm{Ou}$ seja, há um gradiente dentro das iniciativas de consumo colaborativo, podendo elas transitarem entre comportamentos colaborativos e cooperativos.

Para facilitar estudos que precisam quebrar o fenômeno em eventos menores, foram propostos dois fatores que pudessem distinguir o nível de colaboração de uma iniciativa de consumo colaborativo. 
Para isso analisamos várias definições de consumo colaborativo (Botsman \& Rogers, 2011; Hamari et al., 2015; Scaraboto, 2015; Belk, 2014b), e definições de colaboração e cooperação (Axelrod, 1984; Arnold et al., 2012; Kaufman \& Roza, 2013; Jenkins et al., 2014; Hord, 1981; Winey \& Ray, 1994) onde encontramos dois fatores que cruzam os conceitos: (1) uma relação entre consumidores (C2C), (2) um envolvimento pró-social, no que diz respeito a criação de uma comunidade de usuários em torno do acesso a produtos e serviços.

Ao aplicarmos esses fatores em três websites de iniciativas de consumo colaborativo e num site de consumo tradicional, notamos que há uma diferença de atitude dos participantes, tanto entre os sites colaborativos quanto em relação ao site tradicional, o que demonstra que esse gradiente é percebido pelos participantes.

$\mathrm{O}$ que não conseguimos responder aqui é a causa dessa diferença, ou seja, o que nesses sites faz os usuários se sentirem mais ou menos envolvidos com a comunidade e com os pares, ou propensos a se envolver.

Acreditamos que o consumo colaborativo é uma tendência que está se expandindo, visto o suporte tecnológico e a cultura participativa cada vez mais incorporada. O que ainda é nebuloso são os impactos sociais, ambientais, trabalhistas e jurídicos disso. Eckhardt e Bardhi (2015) dizem, por exemplo, que os consumidores estão mais interessados em custos menores e conveniência do que promover relações sociais com empresas ou outros consumidores.

\section{REFERÊNCIAS}

Arnold, N., Ducate, L. \& Kost, C. (2012). Collaboration or cooperation? Analyzing group dynamics and revision processes in wikis. CALICO Journal, 29(3), 431-448.

Axelrod, R. (1984). The evolution of cooperation. New York, NY: Basic Books

Bardhi, F. \& Eckhardt, G. (2012). Access-based consumption: The case of car sharing. Journal of Consumer Research, 39(4), 881-898, 2012.

Barki, H. \& Hartwick, J. (1994). Measuring user participation, user involvement, and user attitude. MIS Quarterly, 18(1), 59-82.

Belk, R. (2007). Why not share rather than own? The ANNALS of the American Academy of Political and Social Science, 611(1), 126-140.

Belk, R. (2009). Sharing. Journal of Consumer Research, 36(5), 715-734.
Belk, R. (2014a). Sharing versus pseudo-sharing in web 2.0. The Anthropologist, 18(1), 7-23.

Belk, R. (2014b). You are what you can access: Sharing and collaborative consumption online. Journal of Business Research, 67(8), 1595-1600.

Botsman, R. \& Rogers, R. (2011). O que é meu é seu: como o consumo colaborativo vai mudar o nosso mundo. Porto Alegre: Bookman

Catarse. (2014). Retrato financiamento coletivo Brasil 2013/2014. Recuperado de http://pesquisa.catarse.me

Eckhardt, G. \& Bardhi, F. (2015). The sharing economy isn't about sharing at all. Harvard Business Review. Recuperado de https://hbr.org/2015/01/the-sharing-economyisnt-about-sharing-at-all

Felson, M. \& Speath, J. (1978). Community structure and collaborative consumption: a routine activity approach. The American Behavioral Scientist, 21(4), 614-624.

Field, A. (2009). Descobrindo a estatística com o SPSS. Porto Alegre: Bookman/Artmed

Hamari, J., Sjöklint, M., \& Ukkonen, A. (2015).The sharing economy: why people participate in collaborative consumption. Journal of the Association for Information Science and Technology, 67(9), 2047-2059.

Hord, S. M. (1981). Working together: cooperation or collaboration? Austin TX: Research and Development Center for Teacher Education. Recuperado http://files.eric.ed.gov/fulltext/ED226450.pdf

Jenkins, H., Ford, S., \& Green, J. (2014). Cultura da Conexão: criando valor e significado por meio da mídia propagável. São Paulo: Aleph.

Kaufman, D. \& Roza, E. (2013). Empresas e consumidores em rede: um estudo das práticas colaborativas no Brasil. São Paulo: Annablume

McCraken, G. (2003). Cultura e consumo: novas abordagens ao caráter simbólico dos bens e das atividades de consumo. Rio de Janeiro: Mauad

Scaraboto, D. (2015). Selling, sharing, and everything in between: the hybrid economies of collaborative networks. Journal of Consumer Research, 42(1), $152-176$

Schor, J. (2014). Debating the sharing economy. A great transition iniciative essay. October. Recuperado de

http://www.tellus.org/pub/Schor_Debating_the_ Sharing_Economy.pdf

Shirky, C. (2011). A cultura da participação: criatividade e generosidade no mundo conectado. Rio de Janeiro.

Sternberg, R. J. (2000). Psicologia cognitiva. Porto Alegre: Artmed.

Walsh, B. (2011). Today's smart choice: Don't own. share. Time Magazine. Recuperado de http://content.time.com/time/specials/packages/ar ticle/0,28804,2059521_2059717,00.html 
Winer. M. \& Ray, K. (1994). Collaboration handbook: creating, sustaining, and enjoying the journey. Saint Paul: Amherst H. Wilder Foundation
Wong, B. (2010). Points of view: Gestalt principles (part 1). Nature Methods, 7(863).

${ }^{1}$ Após realizar um teste estatístico como a ANOVA, o resultado gerado é um valor de $F$ e um valor de p., que afirma se há ou não diferença entre algum dos grupos. Entretanto, o teste não revela onde está a diferença. Para tanto é utilizado um teste post hoc, que indica quais grupos são diferentes de quais, dado que há uma diferença (Field, 2009, p. 322). Alguns gráficos tem a mesma função de um teste post hoc, ou seja, indicar entre quais grupos analisados há uma diferença.

\section{Gradients of collaboration: an exploratory study in collaborative consumption companies websites}

Abstract: This paper outlines a conceptual positioning of the collaborative consumption among the concepts "collaboration" and "cooperation", in order to differentiate collaboration gradients inside collaborative consumption models. In theoretical research, we found a fine line that distinguishes the degrees of collaboration and cooperation by two factors: pro-social involvement level and interaction among consumers. Towards analyzing these gradients empirically, the factors were tested on three collaborative consumption websites and a traditional shopping website. The findings show that the participants perceive differences of involvement between different models of collaborative consumption.

Keywords: Collaborative consumption, Collaboration gradients, Collaboration factors, Cooperation. 